\title{
Corrigentum
}

\section{Comparison of some Adsorbents in Gas-Solid Chromatography}

\section{Vergleich von einigen Adsorbenzien in der Gas-Fest-Chromatographie}

\section{Comparaison de quelques adsorbents en chromatographie gaz-solide}

\author{
B. Versino / F. Geiss \\ EURATOM, Ispra (Varese) Italia
}

Chromatographia 2, 354 (1969)

Fig. 1, page 356

(in the paper the symbols for 1,4-Cylohexadiene and

Benzene Could not distinguished)

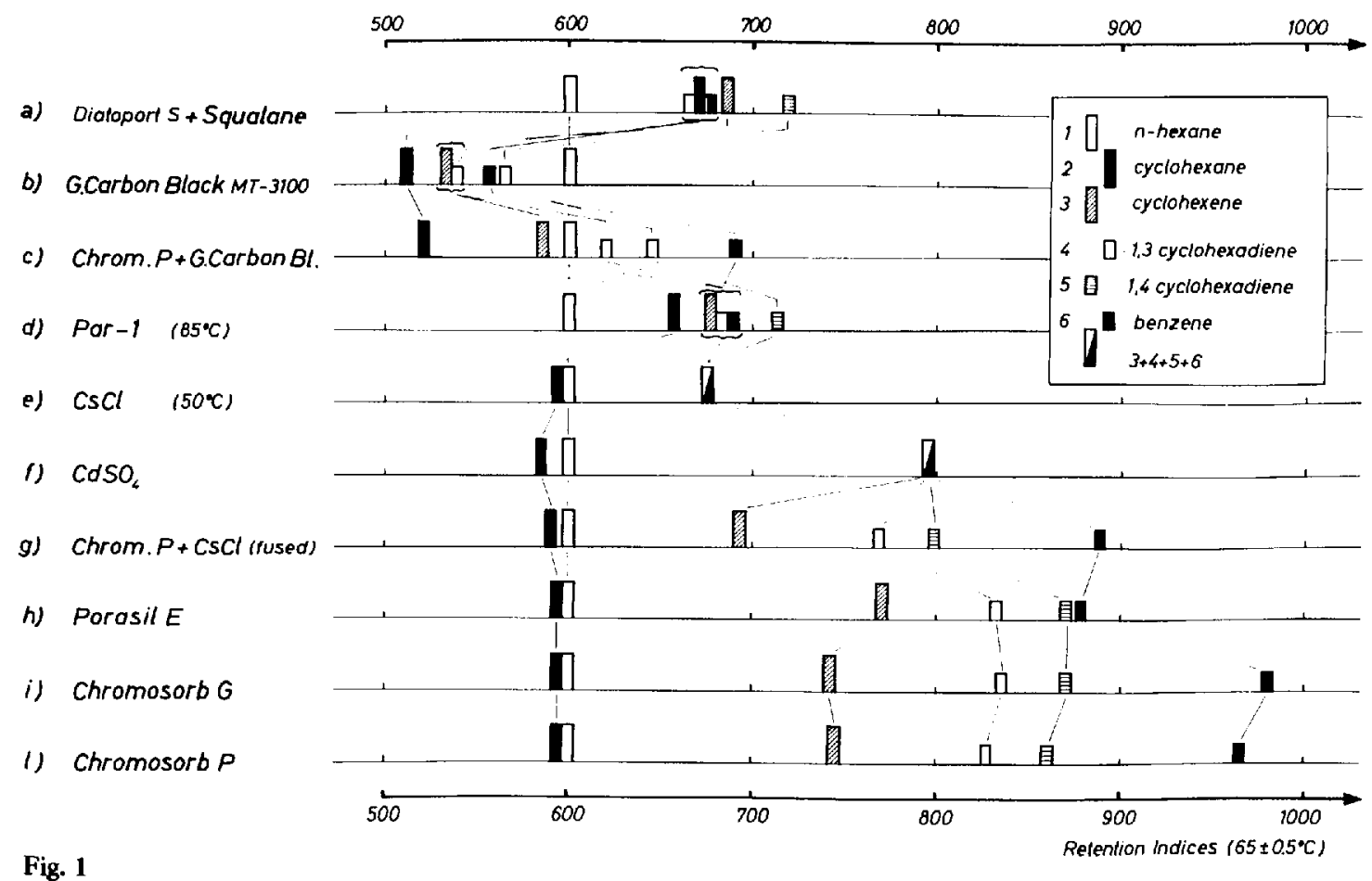

Fig. 1

- Kovats retention indices at $65^{\circ} \mathrm{C}$ for $\mathrm{C}_{6}$-cyclohydrocarbons on different adsorbents. For comparison the data on squalane (partition process) are reported. The relative position of benzene best indicates the transition from specific (c. g. Chromosorbs) to non-specific (e. g. carbon black) interactions.

- Indexwerte $\left(65^{\circ} \mathrm{C}\right)$ für cyclische $\mathrm{C}_{6}$-Kohlenwasserstoffe auf verschiedenen Adsorbenzien. Vergleich mit "Verteilungs"-Werten auf" Squalan. Die relative Stellung des Benzols verdeutlicht am besten den Übergang von spezifischen (z. B. Chromosorb) zu unspezifischen (z. B. graph. Ruß) Wechselwirkungen.

- Indices de rétention Kovats à $65^{\circ} \mathrm{C}$ des hydrocarbures cycliques en $\mathrm{C}_{6}$ sur divers adsorbants. Comme référence les résultats sur squalane (processus de partage) sont ajoutés au graphique. La position relative du benzène permet le mieux de juger la transition entre interactions spécifiques (Chromosorbs) et non spécifiques (charbon)' 